J. Amer. Soc. Hort. Sci. 115(2):302-307. 1990.

\title{
Bud Dormancy Status, Frost Hardiness. Shoot Moisture Content, and Readiness of Black Spruce Container Seedlings for Frozen Storage
}

\author{
Stephen J. Colombo \\ Ontario Ministry of Natural Resources, Ontario Forest Research Institute, Maple, Ont. L6A 1S9, \\ Canada
}

Additional index words. bud morphogenesis, needle primordia, correlated inhibition, rest, electrolyte leakage, Picea mariana

\begin{abstract}
Black spruce [Picea mariana (Mill) B. S. P.] first-year seedlings were exposed to 8-hr photoperiods and warm temperatures (26C maximum, 15C minimum) and tested weekly to determine bud dormancy status, frost hardiness, shoot moisture content, and the amount of damage caused. by a period of frozen storage ( $-3 C)$. Bud dormancy status, frost hardiness, and shoot moisture content were all strongly correlated to the time of bud initiation. Frost hardiness was low ( -5 to $-7.5 \mathrm{C})$ during the period of needle primordia initiation until week 3 ( 3 weeks after $100 \%$ bud initiation), but bud dormancy decreased linearly over this period, from 37 days to budbreak for seedlings sampled at week - 1 (1 week before $100 \%$ of the seedlings had initiated terminal buds) and placed under conditions favoring shoot elongation, to 14 days to budbreak for seedlings sampled on week 3 . From week 5 to week 8 , there was a strong $\left(r^{2}>0.999\right)$ linear correlation between frost hardiness and bud dormancy status. Shoot moisture content declined linearly from $84 \%$ on week -1 to $74 \%$ on week $8\left(r^{2}=0.97\right)$, and shoot moisture content was correlated with both frost hardiness $\left(r^{2}=0.87\right)$ and the percentage of seedlings that suffered needle damage in frozen storage $\left(r^{2}=0.85\right)$. Bud dormancy status, measured as number of days to $50 \%$ budbreak, was curvilinearly correlated with seedling damage following frozen storage, whereas linear relationships with damage in storage were found for dormancy release index $\left(r^{2}=0.92\right)$ and frost hardiness $\left(r^{2}=0.85\right)$.
\end{abstract}

The ability of tree seedlings to endure frozen storage without damage has been empirically related to shoot frost hardiness, bud dormancy status, and shoot moisture content (Ritchie, 1984, 1986; Glerum, 1976; Rossvall-Ahnebrink, 1977), where seedlings that are most dormant or have exceeded critical levels of frost hardiness or shoot moisture content exhibit the best storability. These relationships have practical significance because they may enable the proper timing of tree seedling frozen storage to be predicted by the measurement of these variables. Examples of the use of such attributes for predicting readiness for storage of various species have been given (Ritchie, 1984, 1986; Ritchie et al., 1985; Tinus et al., 1986).

The levels of frost hardiness, bud dormancy, and shoot moisture content required for damage-free frozen storage have been shown to vary among species and for different provenances within a species (Ritchie, 1984, 1986; Ritchie et al., 1985; Rossvall-Ahnebrink, 1977). Therefore, it is important that the relationships between these variables and frozen storage be investigated for new species before the implementation of storage programs. In Canada, nearly all container stock produced, except in British Columbia, is overwintered outside. There is growing interest in the use of frozen storage for overwintering container stock because of the advantages it gives in reducing losses due to shoot desiccation, root freezing, disease, and rodents. Further, seedlings held in storage possess high post-planting stress resistance as a result of remaining dormant through the spring until planting. The purpose of this paper is to describe the relationships between shoot frost hardiness, bud dormancy status, shoot moisture content, and success of frozen storage for 1-year-old black spruce seedlings.

Received for publication 28 Oct. 1988. The cost of publishing this paper was defrayed in part by the payment of page charges. Under postal regulations, this paper therefore must be hereby marked advertisement solely to indicate this fact.

\section{Materials and Methods}

Black spruce seed of a northeastern Ontario general seed collection were sown on a growing medium of 3 peatmoss : 1 vermiculite $(\mathrm{v} / \mathrm{v})$ in $15 \mathrm{FH} 408$ Japanese paperpot trays on 24 and 25 June 1985, and the $=4500$ seedlings produced were grown in a fiberglass-covered greenhouse at the Ontario Forest Research Institute (lat. $43^{\circ} 51^{\prime} \mathrm{N}$, long. $79^{\circ} 31^{\prime} \mathrm{W}$ ), using operational procedures similar to those described by Carlson (1983). Each seedling grew in its own 70-ml cavity, with 336 cavities composing each tray. Natural daylengths during the seedling rearing period were supplemented with low-intensity incandescent light to extend the photoperiod to $18 \mathrm{hr}$. The night minimum was $15 \mathrm{C}$ and days usually were between 22 and 26C, although on several days temperatures briefly rose to between 30 and $35 \mathrm{C}$, when both solar radiation and ambient temperatures were high.

The seedling rearing period ended and hardening, which was conducted in the greenhouse, began on 28 Oct. 1985, 18 weeks after sowing, at which time fertilizer was leached from the growing medium and fertilization and supplemental lighting were halted to induce terminal bud initiation. At the same time, night length was increased to $16 \mathrm{hr}$ by the use of artificial shades operated manually from Monday to Friday every week until completion of the trial (excluding three nights coinciding with statutory holidays). Temperatures during the seedling hardening period remained within the range $26 \mathrm{C}$ day maximum and $15 \mathrm{C}$ night minimum. Seedlings were inadvertently exposed to low-intensity incandescent light at night whenever shades were not used between 28 Oct. and 4 Dec., which prolonged the time required to reach $100 \%$ bud initiation in the crop to 5 weeks ( 2 to 3 weeks is normal), but otherwise seedlings behaved similarly to those in other trials (Colombo et al., 1982; Colombo and Cameron, 1986). Following terminal bud initiation in all seedlings on 2 Dec. 1985 (determined by sequential destructive sampling for dissection and examination of shoot apices under a binocular 
microscope to observe differentiated budscales), fertilization was resumed at a low rate. The hardening period was terminated 2 Jan. 1986, 8 weeks past the date of $100 \%$ bud initiation, as this has been found previously to have allowed significant increases in shoot frost hardiness and storability to occur (Colombo et al., 1984; Colombo and Cameron, 1986).

Seedlings were sampled and placed in frozen $(-3 C)$ storage weekly, beginning 25 Nov., 4 weeks after the start of the hardening period. From 30 to 44 randomly selected seedlings (two or three per tray) were carefully removed from their trays with paperpot. containers intact and were sealed in a polyethylenelined waxed fiberboard box. A new box of seedlings was prepared and placed in frozen storage each week for 8 weeks until the end of the hardening period on 30 Jan. 1986.

Determinations of shoot frost hardiness of seedlings in the greenhouse were made weekly beginning 28 Oct. 1985, at the end of the seedling rearing period, and continuing until the end of the hardening period on 30 Jan. 1986. Shoot frost hardiness was determined using the index of injury-electrical conductivity technique (Flint et al., 1967; Colombo et al., 1984). This technique is predicated upon freezing damage being indicated by an increase in a bathing solution's electrical conductivity due to freezing damage to plant cell membranes, allowing leakage of ionic contents from the tissue (Levitt, 1980). Previous studies have shown that good correlations exist between index of injury and whole-plant estimates of freezing damage based on visual signs of injury (Aronsson and Eliasson, 1970; Colombo et al., 1982; Green and Warrington, 1978). To estimate index of injury, the terminal 2 to $3 \mathrm{~cm}$ of the main shoot of 45 randomly selected seedlings (three seedlings per tray) was excised, with three shoot tips being placed in each of 15 test tubes. Sufficient distilled water $(30 \mathrm{ml})$ to cover the shoot tips was added to each test tube to allow electrolyte leakage before damage by freezing. After $16 \mathrm{hr}$ of room temperature incubation, the water was measured for electrical conductivity $\left(\mathrm{EC}_{\text {control }}\right)$, decanted, and saved for later use. Shoot tips were then frozen at a rate of $5 \mathrm{C} / \mathrm{hr}$. Five -test tubes were removed from the freezer at each of three preselected temperatures, expected to span the range of nondamaged to severely damaged shoot tips, and were placed in a cool room (10 to $15 \mathrm{C})$ to thaw for 2 to $4 \mathrm{hr}$. Following thawing, the previously decanted solutions were returned to the same test tubes from which they were taken. After $16 \mathrm{hr}$ of incubation, the electrical conductivity of the water was remeasured to determine $\mathrm{EC}_{\text {frozen }}$. After measurement of $\mathrm{EC}_{\text {frozen }}$, the test tubes, containing water and shoot tips, were capped and placed in a 90C oven for $4 \mathrm{hr}$ to kill the tissues and allow leakage of the tissue's total content of ions. $\mathrm{EC}_{\text {killed }}$ was measured following incubation of the killed samples for $16 \mathrm{hr}$. Index of injury $\left(\mathrm{I}_{\mathrm{t}}\right)$ was estimated as

$$
\left.\mathrm{I}_{\mathrm{t}}=\left(\mathrm{EC}_{\text {frozen }}-\mathrm{EC}_{\mathrm{control}}\right) / \mathrm{EC}_{\text {killed }}\right) \times 100
$$

where $I_{t}$ and damage to shoot tips from freezing were inversely proportional (Columbo etet. al., 1982). Frost hardiness was defined as the minimum temperature resulting in an $\mathrm{I}_{\mathrm{t}} \leq 5 \%$, a threshold above which higher levels of It are usually associated with visible symptoms of freezing damage.

Shoot moisture content was estimated using the same shoot tips used in testing electrolyte leakage. Shoot tip fresh weights were determined at the time of collection. Following the determination of electrolyte leakage $\left(\mathrm{EC}_{\mathrm{killed}}\right)$, the shoot tips were air-dried for $24 \mathrm{hr}$ before being oven-dried ( $48 \mathrm{hr}$ at 90C) and remeasured to determine oven dry weight. Moisture content could not be determined for the week of 23 Dec., as the samples were inadvertently discarded. Moisture content of each group of three shoot tips was calculated as:

$$
\begin{gathered}
\text { Moisture content }(\%)=(\text { fresh weight }- \text { oven-dry } \\
\text { weight }) /(\text { fresh weight }) \times 100
\end{gathered}
$$

The use of shoot tips that have been killed and leached for dry weight determinations underestimates dry weight compared to the use of the nonleached samples.

Dormancy status of the terminal buds of seedlings was estimated by determining the number of days to budbreak in $50 \%$ of a sample of seedlings placed into conditions favoring shoot elongation. Twenty seedlings per week (one to two seedlings per tray) were selected randomly and carefully removed from the trays in the greenhouse with paperpot plugs and roots intact, and were potted in peatmoss with 10 seedlings in each of two 1-liter pots and placed in a growth chamber (Conviron E7; 16 $\mathrm{hr}$ daylength provided by a mix of fluorescent and incandescent bulbs providing a photosynthetic photon flux density of $\approx 200$ $\mu \mathrm{M}$ photons $/ \mathrm{m}^{2}$ per sec and a constant temperature of $20 \mathrm{C}$ ). Seedlings were not sampled 30 Dec. to determine bud dormancy status due to scheduling difficulties. Twice weekly, after being placed in the growth chamber, the terminal buds were visually examined to determine whether budbreak had occurred. Buds were considered broken when the bud scales had parted to reveal the enclosed primordial shoot. The mean number of days for $50 \%$ of the seedlings to break bud was taken as being directly proportional to the intensity of bud dormancy. A 50\% dormancy release index $\left(\mathrm{DRI}_{50}\right)$ for each sample was calculated using a procedure analogous to that of Ritchie (1984), where

$$
\mathrm{DRI}_{50}=4.5 / \mathrm{DBB}_{50}
$$

and the numerator, 4.5 , is the number of days for $50 \%$ of quiescent 1-year-old black spruce seedlings to break bud (unpublished data), and $\mathrm{DBB}_{50}$ is the mean number of days for $50 \%$ of a sample of seedlings to break bud.

The effects of frozen storage on seedlings were evaluated by a visual assessment of needle damage 28 days after seedlings were placed under favorable growing conditions in a greenhouse. All seedlings were removed from storage on 1 May 1986, and allowed to thaw for $24 \mathrm{hr}$ sealed in boxes in a cool room (15 to 20C). Following thawing, the seedlings were removed from boxes, planted in peatmoss in 4-liter pots, and placed in a greenhouse (16-hr daylength provided by supplemental highintensity sodium vapor lamps, at a constant 20 to $25 \mathrm{C}$ ). After 28 days in the greenhouse, the number of seedlings to have suffered damage, as shown by the presence of dead needles, was assessed.

\section{Results and Discussion}

Seedling shoots were frost-hardy $\left[\mathrm{I}_{\mathrm{t}},<5 \%\right.$ (Colombo et al., 1984)] to -5 or $-7.5 \mathrm{C}$ up to the 3 rd week past $100 \%$ bud initiation (Fig. 1A). There was a linear increase in frost hardiness $\left(r^{2}=0.959\right)$ with time between weeks 3 and 8 , with frost hardiness increasing from $-7.5 \mathrm{C}$ on week 3 to $-40 \mathrm{C}$ on week 8. Shoot moisture content also decreased linearly over time $\left(\mathrm{r}^{2}\right.$ $=0.974)$, ranging from $83.9 \%$ on week -1 to $74.5 \%$ on week 8 (Fig. ID). In contrast, $\mathrm{DBB}_{50}$ decreased linearly at two different rates, before and after week 4 (Fig. 1B). Before week 4, $\mathrm{DBB}_{50}$ decreased rapidly, from 37 days to $50 \%$ budbreak for seedlings collected on week -1 , to 14 days to $50 \%$ budbreak 

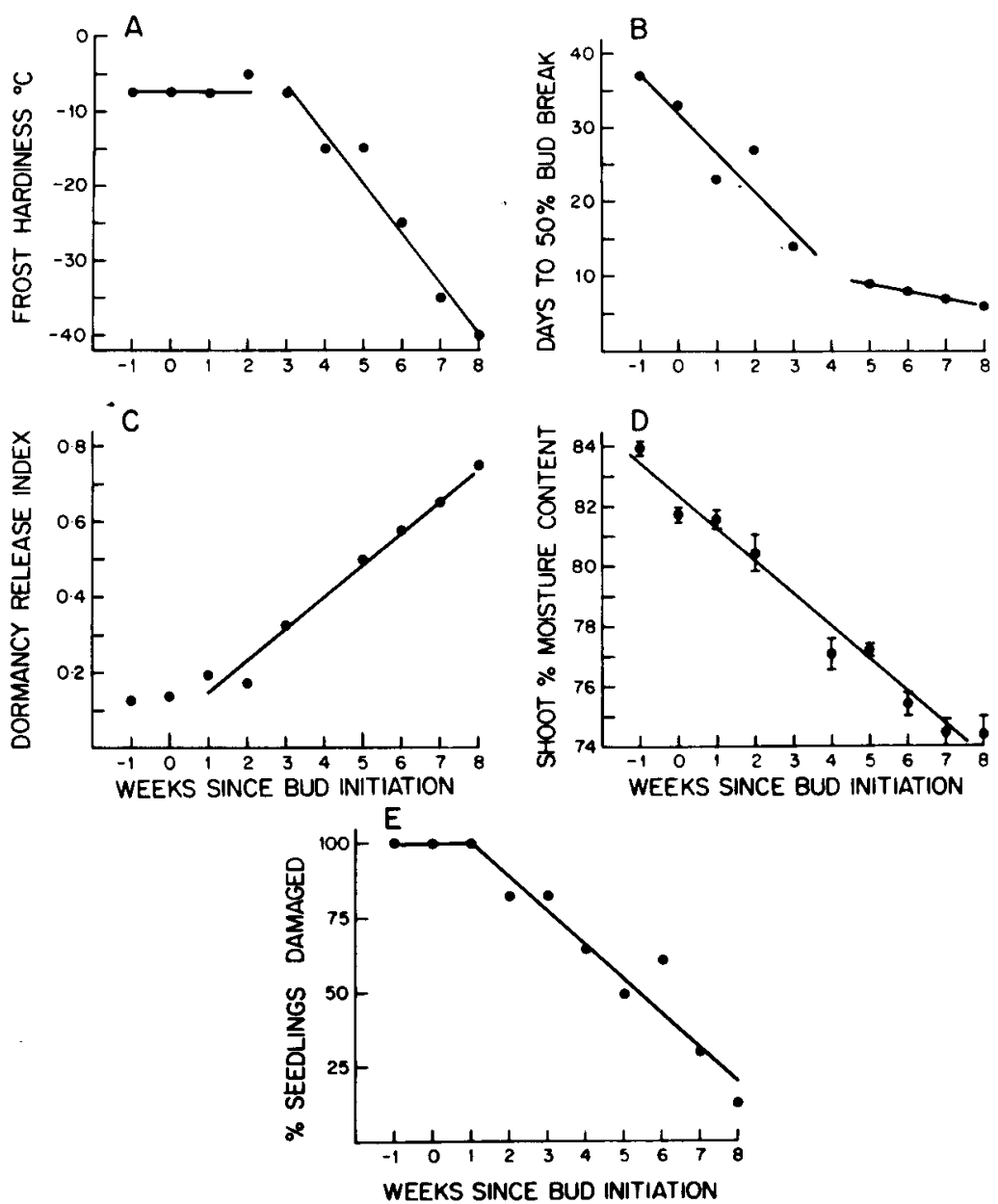

Fig. 1. Relationship between time since bud initiation in first-vear black spruce seedlings and (A) shoot frost hardiness. For weeks 3 through $8, \mathrm{y}=13.62-$ $6.64 \mathrm{x}, r^{2}=0.959$. (B) Days to $50 \%$ terminal budbreak under non-bud-inductive daylengths. For weeks -1 through $3, \mathrm{y}=32.0-2.6 \mathrm{x}, r^{2}=0.843$; for weeks 5 through $8, \mathrm{y}=14.0-$ lox, $r^{2}>0.999$. (C) Dormancy release index of the terminal bud. For weeks 1 through $8, y=0.063+0.084 x, r^{2}=$ 0.977. (D) Percent moisture content $(+$ SES $)$ of the shoot tip. For all weeks, $\mathrm{y}=82.34-1.079 \mathrm{x}, r^{2}=$ 0.974. (E) Percentage of seedlings suffering needle damage following frozen storage at $-3 \mathrm{C}$. For weeks 1 through $8, \mathrm{y}=112.07-11.49 \mathrm{x}, r^{2}=0.910$.

for seedlings collected week $3\left(\mathrm{r}^{2}=0.843\right)$. Following week $4, \mathrm{DBB}_{50}$ decreased slowly, decreasing from 9 days to $50 \%$ budbreak for seedlings collected week 5, to 6 days for seedlings collected week $8\left(\mathrm{r}^{2}=0.999\right)$. Dormancy release index (DRI) increased linearly $\left(r^{2}=0.977\right)$ between weeks 1 and 8 , while DRI did not increase proportionately on weeks -1 and $\mathrm{O}$ (Fig. $1 C)$.

The dormancy period of shoot apical meristems is considered to occur in a series of stages, because, despite all stages being characterized in most temperate-zone tree species by the presence of a terminal bud, there is a range of differing physiological states that occur throughout the dormant period (Fuchigami et al., 1982; Glerum, 1976; Lavender, 1984; Romberger, 1963; Vegis, 1964). In this paper, the definition of dormancy is similar to that of Romberger (1963), in which three dormant states are considered: correlated inhibition, rest, and quiescence. The onset of correlated inhibition is identified morphogenetically by the differentiation of budscales at the apical shoot meristem, marking the transition from the active to the dormant period of the annual shoot growth cycle. In young seedlings of Picea spp., the initiation of correlated inhibition is usually cued by environmental stimuli, such as shortening photoperiods, water, and nutrient stresses (Lavender, 1984). Buds are generally considered most dormant if they are in a state of rest (Fuchigami et al., 1982; Lavender, 1984; Ritchie, 1986; Romberger, 1963; Vegis, 1964), and the onset of rest has also been defined as the point at which frost hardiness begins to increase (Nissila and Fuchigami, 1978). Seedlings are quiescent if the chilling re- quirement has been fully satisfied and the dormant condition is imposed entirely by the environment and not by seedling physiological constraints.

In the present trial, seedlings were examined through correlated inhibition and probably into rest. Dormancy intensity, as measured by $\mathrm{DBB}_{50}$ and DRI, declined from a maximum at week -1 to a minimum on week 8 (Fig. 1 B and C). Seedlings in the early stages of correlated inhibition were most dormant, as they were slowest to break bud upon being placed in longday conditions. Similar relationships for greenhouse-grown, firstyear seedlings of Picea engelmanii (Parry) Engelm., Pinus ponderosa Laws., and Pseudotsuga menziesii var. glauca (Beissn.) Franco have been observed by Tinus et al. (1986).

The question of whether physiological links exist between frost hardiness and bud dormancy, or whether they are merely temporally related, cannot be answered directly. The existence of functional relationships has been the object of speculation, but of little direct experimental investigation (Glerum, 1976; Nissila and Fuchigami, 1978; Ritchie, 1984, 1986, 1987; Smith and Kefford, 1964; Tinus et al., 1986). In this trial, frost hardiness was curvilinearly associated with DRI (Fig. 2 A and B), where:

$$
\begin{gathered}
(\mathrm{DRI})^{2}=-0.052-0.015 \text { frost hardiness }\left({ }^{\circ} \mathrm{C}\right) ; \\
\mathrm{r} 2=0.950
\end{gathered}
$$

This relationship, however, should only be taken as evidence of an empirical, rather than a functional relationship before week 4, since, as shown in Figs. $1 \mathrm{~A}$ and $\mathrm{B}$ and $2 \mathrm{~A}$, the greatest 

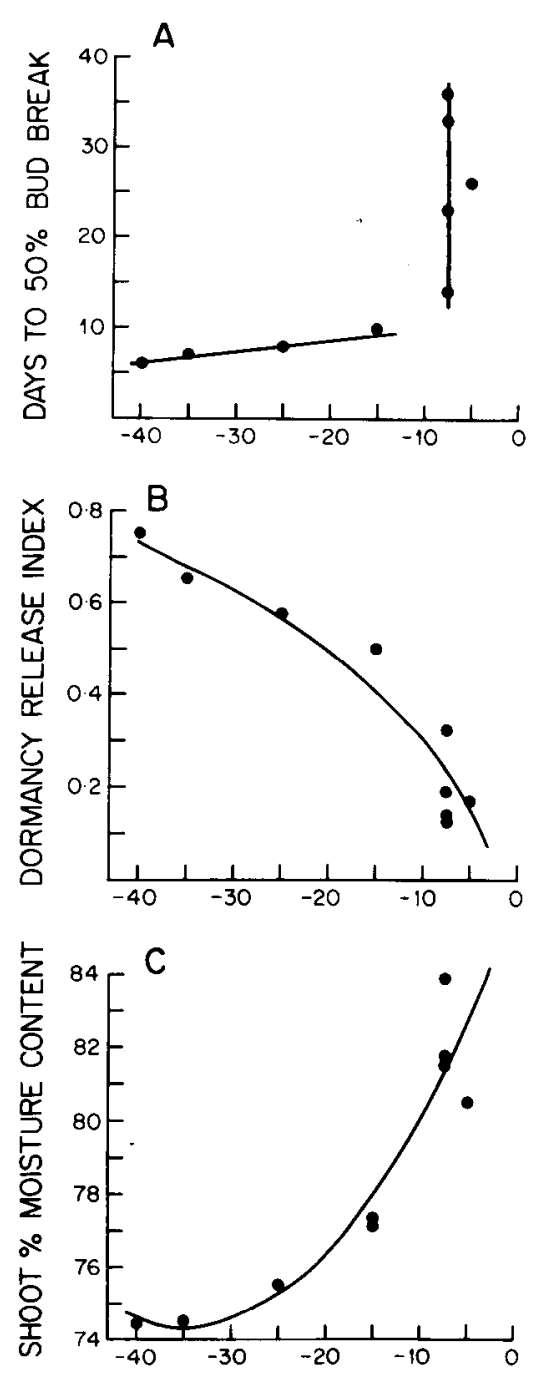

FROST HARDINESS $\left({ }^{\circ} \mathrm{C}\right)$

Fig.2. Relationship between frost hardiness of the shoot tip of firstyear black spruce seedlings during bud development and (A) days to $50 \%$ terminal budbreak under non-bud-inductive daylengths. For weeks 5 through $8, \mathrm{y}=10.81+0.115 \mathrm{x}, r^{2}=0.980$. (B) Dormancy release index of the terminal bud. For all weeks, $\mathrm{y}^{2}=-0.052$ $-0.015 \mathrm{x}, r^{2}=0.952$. (C) Percent moisture content of the shoot tip. For all weeks, $\mathrm{y}=85.65+0.652 \mathrm{x}+0.0094 \mathrm{x}^{2}, r^{2}=0.867$.

declines in $\mathrm{DBB}_{50}$ occurred between weeks -1 and 3 , over which time there were no increases in frost hardiness.

A case for the existence of a common physiological link between frost hardiness and bud dormancy status can be made for the period from week 5 to week 8 , during which time frost hardiness increased from $-15 \mathrm{C}$ to $-40 \mathrm{C}$. At the same time as frost hardiness was increasing following week 4, bud dormancy was decreasing proportionately, with an $\mathrm{r}^{2}$ of 0.980 from linear regression between $\mathrm{DBB}_{50}$ and frost hardiness. Similar observations have been made by Tinus et al. (1986), although greater similarities in results between their trial and this one might have been found had they conducted their bud dormancy status tests using constant rather than ambient daylengths, since daylengths can affect rates of budbreak (Neinstaedt, 1966; Worrall and Mergen, 1967). Neither increasing frost hardiness nor decreasing bud dormancy in the present trial required exposure to low temperature to proceed. The change between weeks 3 and 5 is interpreted as marking the transition from correlated inhibition to rest.

During what is, therefore, proposed to be correlated inhibition (i.e., prior to week 4), frost hardiness levels were low, presumably due to high levels of physiological activity within the newly initiated terminal bud. On a cellular level, this period of bud morphogenesis is characterized by high levels of mitotic activity associated with needle primordia initiation (Carlson et al., 1980; Owens and Molder, 1973a, 1973b), and correlations of frost hardiness with needle primordia initiation (Colombo et al., 1982) and mitotic index (Colombo et al., 1989) have previously been found. In addition, the cessation of needle primordia initiation has been observed to be correlated with increases in frost hardiness (Colombo et al., 1982, 1984). In this study, needle primordia initiation was complete by week 4 (unpublished data), corresporiding to the beginning of an increase in frost hardiness. If, in fact, the end of needle primordia initiation in first-year black spruce seedlings marked the onset of rest, our observations would suggest that frost hardiness was inversely correlated to dormancy intensity once a state of rest had been attained. This observation is in contrast to Ritchie's (1987) that frost hardiness is greatest at intermediate levels of dormancy intensity for 2-year-old Douglas fir.

Declining shoot moisture content over time was correlated with increasing frost hardiness $\left(r^{2}=0.870\right)$ and decreasing damage in storage $\left(\mathrm{r}^{2}=0.893\right)$ (Figs. 2C and 3D). Declining moisture content following bud initiation is attributed to decreasing shoot moisture content at full hydration, not to an increasing water saturation deficit, since seedlings were collected early in the day from a warm, humid greenhouse, with plants in a moist growing medium. Seasonal declines in shoot moisture content are attributable to an increase in shoot tip dry matter due to cell wall thickening, signification of secondary xylem, and augmentation of proteins and sugars in the cytoplasm (Levitt, 1980). Increasing frost hardiness with seasonally declining moisture content has been noted for a wide range of woody species (Gusta and Weiser, 1972; Pellett and White, 1969; Rossvall-Ahnebrink, 1977; Timmis and Worrall, 1975; Wolpert and Howell, 1985, 1986). In the present trial, the decline in shoot moisture content was concurrent with increases in frost hardiness to between -15 and $-25 \mathrm{C}$, below which further changes in moisture content were nonsignificant, while frost hardiness continued to increase.

The ability of black spruce seedlings to survive frozen storage without damage increased linearly $\left(r^{2}=0.910\right)$ from week 1 to 8 (Fig. 1E), and was significantly correlated to shoot moisture content, frost hardiness, and bud dormancy status (Fig. 3 AD). Best survival was achieved when seedlings were put in storage on week 8 , when they had least moisture content, and were most frost-hardy and least dormant. Shoot moisture content (Fig. 3D) was curvilinearly correlated to the percentage of seedlings that suffered damage in frozen storage $\left(r^{2}=0.893\right)$; however, this criterion lacked sensitivity to predict seedling readiness for storage, since the decline in seedling damage from frozen storage from $30 \%$ to $10 \%$ was marked by a change in shoot moisture content of $<0.5 \%$. Bud dormancy status measured as number of days to $50 \%$ budbreak was also curvilinearly related to seedling damage following frozen storage (Fig. 3B), while a linear correlation $\left(r^{2}=0.918\right)$ between dormancy release index and damage in storage existed (Fig. 3C). However, as for shoot moisture content, the relationship between bud dormancy status and damage in storage was marked by a large change in damage for small changes in bud dormancy. In con- 

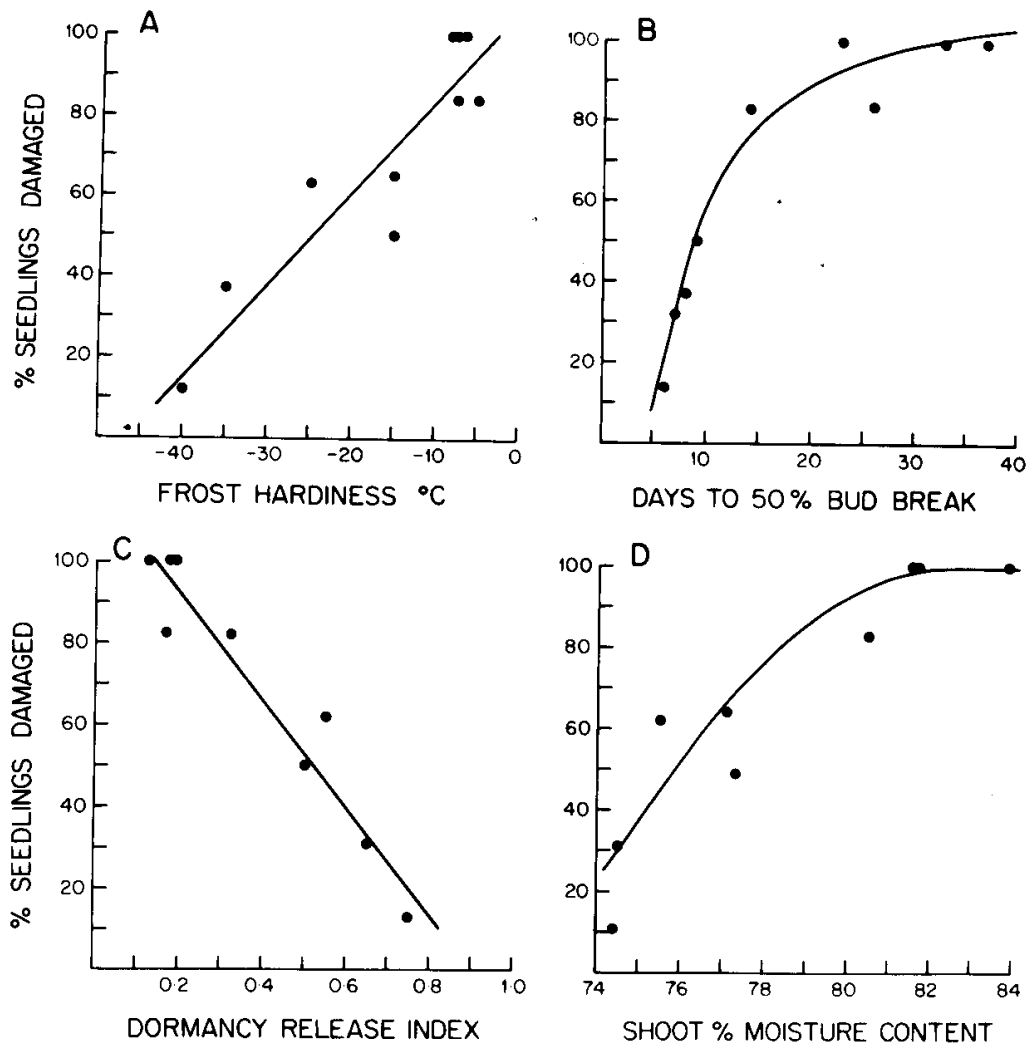

Fig. 3. Relationship between the percentage of firstyear black spruce seedlings suffering needle damage following frozen storage at $-3 \mathrm{C}$ and (A) shoot frost hardiness. For all weeks, $\mathrm{y}=105.57+2.259 \mathrm{x}, r^{2}$ $=0.846$. (B) Days to50\%terminal budbreak under non-bud-inductive daylengths. (C) Dormancy release index of the terminal bud. For all weeks, $y=118.01$ - 130.54x, $r^{2}=0.918$. (D) Percent moisture content of the shoot tip. For all weeks, $\arcsin (\mathrm{y} / 100)=7.58$ $+9.37 \arcsin (\mathrm{x} / 100), r^{2}=0.893$

trast, frost hardiness waslinearly correlated to damage following frozen storage $\left(r^{2}=0.850\right)$, with an increase in frost hardiness from -35 to $-40 \mathrm{C}$ being related to a decline in seedling damage in storage from $31 \%$ to $10.5 \%$. Using multiple regression, an $r^{2}$ of 0.923 resulted from the prediction of damage following frozen storage where frost hardiness and bud dormancy status were dependent variables, where:

arcsin damage $(\% / 100)=116.50-104.35$ (dormancy release index) +0.503 (frost hardiness)

The best predictor of damage from frozen storage, however, was derived using the function:

logit damage $(\%)=123.73-70.69 \mathrm{a}+\mathrm{b}[$ logit shoot moisture content $(\%)]+13.68$ (log frost hardiness) [6]

A total of $97.2 \%$ of the variability in damage from frozen storage was explained using this function.

The following conclusions and hypotheses may be drawn from the results of this trial: 1) There is considerable value in using time of bud initiation and end of bud development as morphological markers for seedling physiological conditions. 2) The end of needle primordia initiation marked the beginning of frost hardening and the transition from a state of correlated inhibition to rest. 3) Best storage was accomplished using seedlings that were near the end of rest and approaching a quiescent state. 4) Bud dormancy declined and frost hardiness increased without the necessity of cold-temperature exposure. 5). Small changes (i.e., $<0.5 \%$ ) in shoot moisture content were associated with large changes in frost hardiness and damage caused by frozen storage. 6) Terminal buds were most dormant when they had first been initiated, when bud dormancy status was measured as the number of days to budbreak under favorable conditions.

\section{Literature Cited}

Aronsson, A. and L. Eliasson. 1970. Frost hardiness in Scots pine (Pinus sylvestris L.): I. Conditions for test on hardy plant tissues and for evaluation of injuries by conductivity measurements. Stud. For. Succ. 77.

Carlson, L.W. 1983. Guidelines for rearing containerized tree seedlings in the Prairie provinces. Env. Can., North. For. Res. Cent. Info. Rpt. NOR-X-214E.

Carlson, W. C., W.D. Binder, C.O. Feenan, and L. Preisig. 1980, Changes in mitotic index during onset of dormancy in Douglas-fir seedlings. Can. J. For. Res. 10:371-378.

Christersson, L. 1978. The influence of photoperiod and temperature on the development of frost hardiness in seedlings of Pinus sylvestris and Picea abies. Physiol. Plant. 44:288-294.

Colombo, S.J. and R.C. Cameron. 1986. Assessing readiness of black spruce container seedlings for frozen storage using electrical impedance, oscilloscope square wave and frost hardiness techniques. Ont. Min. Nat. Resources, For. Res. Note 42.

Colombo, S. J., C. Glerum and D.P. Webb. 1989. Winter hardening in black spruce (Picea mariana) seedlings. Physiol. Plant. 76:1-9.

Colombo, S. J., D.P. Webb, and C. Glerum. 1982. Cold hardiness and bud development under short days in black and white spruce seedlings, p. 171-176. In: J.B. Scarratt, C. Glerum, and C.A. Plexman (eds.). Proc. Canadian containerized tree seedling symposium. Environment Canada, Can. For. Serv. COJFRC Symp. Proc. O-P-10.

Colombo, S. J., D.P. Webb, and C. Glerum. 1984. Frost hardiness testing: An operational manual for use with extended greenhouse culture. Ontario Min. Nat. Resour., For. Res. Rep. 110.

Flint, H. L., B.R. Boyce, and D.J. Beattie. 1967. Index of injury-A useful expression of freezing injury to plant tissues as determined by the electrolytic method. Can. J. Plant Sci. 47:229-230.

Fuchigami, L. H., C.J. Weiser, E. Kobayashi, R. Timmis, and L. Gusts. 1982. A degree growth stage $\left({ }^{\circ} \mathrm{GS}\right)$ model and cold acclimation in temperate woody plants, p. 93-1 16, In: P.H. Li and A. Sakai (eds.). Plant cold hardiness and freezing stress. vol. 2. Academic, New York. 
Glerum, C. 1976. Frost hardiness of forest trees, p. 403-420. In: M.G.R. Cannell and F.T. Last (eds.). Tree physiology and yield improvement. Academic, New York.

Glerum, C. 1982. Frost hardiness and dormancy in conifers. Proc. Northeastern Area Nurserymen's Conf. Nova Scotia Dept. Lands and Forests, Truro, N.S. p. 37-46.

Green, L.M. and I.J. Warrington. 1978. Assessment of frost damage in radiata pine seedlings using the diffusate electroconductivity technique. N.Z. J. For. Sci. 8:344-350.

Gusta, L.V. and C.J. Weiser. 1972. Nucleic acid and protein changes in relation to cold acclimation and freezing injury of Korean boxwood leaves. Plant Physiol. 49:91-96.

Lavender, D.P. 1984. Bud dormancy, p. 7-15. In: M.L. Duryea (cd.). Evaluating seedling quality: Principles, procedures and predictive abilities of major tests. Forest Research Lab., Oregon State Univ., Corvallis.

Levitt, J. 1980. Responses of plants to environmental stresses. Chilling, freezing and high temperature stresses. vol. 1. 2nd ed. Academic, Toronto.

Nienstaedt, H. 1966. Dormancy and dormancy release in white spruce. For. Sci. 12:374-384.

Nissila, P.C. and L.H. Fuchigami. 1978. The relationship between vegetative maturity and the first stage of cold acclimation. J. Amer. Soc. Hort. Sci. 103:710-711.

Owens, J.N. and M. Molder. 1973a. A study of DNA and mitotic activity in the vegetative apex of Douglas-fir during the annual growth cycle. Can. J. Bet. 51:1395-1409.

Owens, J.N. and M. Molder. 1973b. Bud development in western hemlock: I. Annual growth cycle of vegetative buds. Can. J. Bet. 51:2223-2231.

Pellett, N.E. and D.B. White. 1969. Relationship of seasonal tissue changes to cold acclimation of Juniperus chinensis 'Hetzi'. J. Amer. Soc. Hort. Sci. 94:460-462.

Ritchie, G.A. 1984. Effect of freezer storage on bud dormancy release in Douglas-fir seedlings. Can. J. For. Res. 14:186-190.

Ritchie, G.A. 1986. Relationships among bud dormancy status, cold hardiness and stress resistance in $2+0$ Douglas-fir. New Forests $1: 29-42$.

Ritchie, G.A. 1987. Relationships among bud dormancy status, cold hardiness and stress resistance in $2+0$ Douglas fir. New Forests 1:29-42.

Ritchie, G. A., J.R. Roden, and N. Kleyn. 1985. Physiological quality of lodgepole pine and interior spruce seedlings: Effects of lift date and duration of freezer storage. Can. J. For. Res. 15:636-645.

Romberger, J.A. 1963. Meristems, growth and development in woody plants. USDA For. Serv., Tech. Bul. 1293.

Rossvall-Ahnebrink, G. 1977. Artificial hardening of spruce and pine seedlings in plastic greenhouses. The Royal College of Forestry, Garpenberg, Sweden, Inst. For. Genetics Intl. Rapporter 1978-14. (Can. Dept. Environ. Library Serv. Translation 00ENV TR-1874.) p. 153-161.

Timmis, R. and J. Worrall. 1975. Environmental control of cold acclimation in Douglas fir during germination, active growth and rest. Can. J. For. Res. 5:464-477.

Tinus, R, W., K. E. Burr, S. J, Walhrer, and R.M:-King. 1986. Relation between cold hardiness, root growth capacity, and bud dormancy in three western conifers, p. 80-86. In: T.D. Landis (cd.). Proc. Combined Western Forest Nursery Council and Intermountain Nursery Assn. Mtg. USDA Forest Serv. Gen. Tech. Rpt. RM-137.

Vegis, A. 1964. Dormancy in high plants. Annu. Rev. Plant Physiol. 15:185-224.

Weiser, C.J. 1970. Cold resistance and injury in woody plants. Science 169:1269-1277.

Wolpert, J.A. and G.S. Howell. 1985. Cold acclimation of Concord grapevines: $H$. Natural acclimation pattern and tissue moisture decline in canes and primary buds of bearing vines. Amer. J. Enol. Viticult. 36:189-194.

Wolpert, J.A. and G.S. Howell. 1986. Cold acclimation of Concord grapevines: 111. Relationship between cold hardiness, tissue water content and shoot maturation. Vitis 25:151-159.

Worrall, J. and F. Mergen. 1967. Environmental and genetic control of dormancy in Picea abies. Physiol. Plant. 20:733-745. 